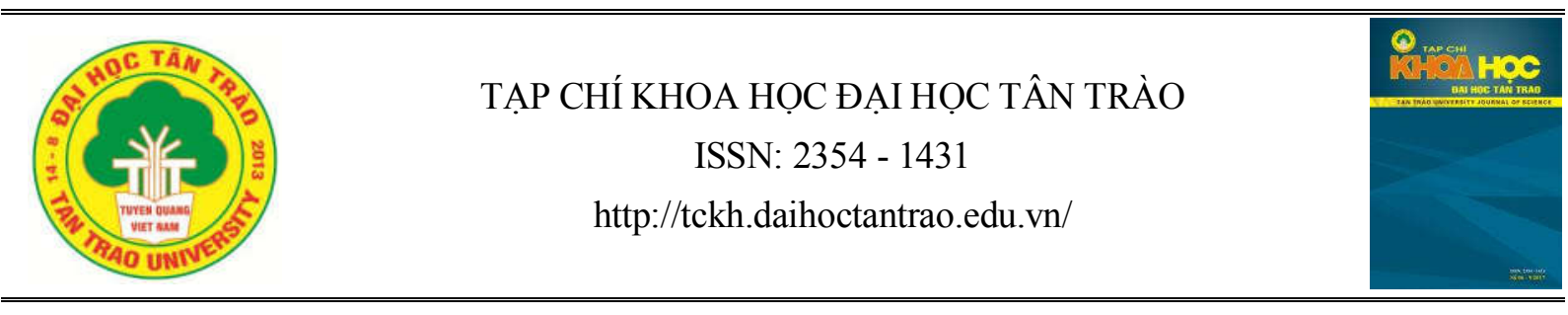

\title{
Vận dụng hoạt động trải nghiệm trong dạy học tiếng Việt cho lưu học sinh Lào ở Trường Đại học Tân Trào
}

\author{
Nguyễn Mỹ Việt $t^{*}$ \\ ${ }^{a}$ Trường Đại học Tân Trào \\ *Email: nguyenmyviettq@gmail.com
}

\section{Thông tin bài viết}

Ngày nhận bài:

25/5/2019

Ngày duyệt đăng:

$10 / 6 / 2019$

Tì khóa:

Kinh nghiệm sáng tạo, năng lục; đàm thoai; giảng dạy tiếng Việt; sinh viên Lào

\section{Tóm tắt}

Kinh nghiệm sáng tạo là một hoạt động trong lý thuyết. Đó là, người học thông qua các hoạt động học tập, hình thành những khả năng và phẩm chất nhất định và chỉ tồn tại, phát triển con người và xã hội. Dựa trên cơ sở lý thuyết của giáo dục hiện đại về các hoạt động trải nghiệm sáng tạo, bài viết xây dựng quy trình tổ chức các hoạt động trải nghiệm sáng tạo trong giảng dạy đàm thoại trong chương trình tiếng Việt cho sinh viên Lào. Từ đó, giúp họ phát huy khả năng sử dụng tiếng Việt trong hội thoại và trong khi học tập, nghiên cứu tại Đại học Tân Trào, tỉnh Tuyên Quang.

\section{1. Đặt vấn đề}

Hiện nay, trong các xu hướng quốc tế về cải cách giáo dục, định hướng phát triển năng lực cho học sinh là một trong những xu hướng trọng tâm. Theo lí luận dạy học hiện đại, năng lực (competency) không thể có được thông qua dạy, mà phải thông qua học, luyện tập [1]. Vì thế, vai trò của trải nghiệm trong giáo dục rất được coi trọng. Đây được coi là quan điểm giáo dục được thế giới đề cao, các nước: Hàn Quốc, Trung Quốc, Singapore, Australia, Anh... đã đưa hoạt động trải nghiệm vào chương trình giáo dục từ rất sớm và đạt hiệu quả cao. Trên cơ sở tìm hiểu về mặt lí luận và thực tiễn của hoạt động trải nghiệm trong giáo dục, bài viết nhằm mục tiêu xây dựng quy trình tổ chức hoạt động trải nghiệm trong dạy học phần Hội thoại trong chương trình Tiếng Việt $c o$ s sở dành cho lưu học sinh Lào. Từ đó, giúp các em phát triển năng lực sử dụng tiếng Việt trong hội thoại và trong khi học tập, nghiên cứu tại trường Đại học Tân Trào, tỉnh Tuyên Quang.

\section{Nội dung}

\subsection{Hoạt động trải nghiệm trong dạy học}

Lí thuyết về hoạt động trải nghiệm trong giáo dục đã có từ lâu trên thế giới. Nhiều nhà tâm lý học, giáo dục học nghiên cứu về hoạt động này trên nhiều phương diện khác nhau như Lev Vygotsky, Jean Piaget,
John Deway... Đặc biệt, David Kolb đã xây dựng thành công lý thuyết học từ trải nghiệm (Experiential learing) [2]. Nhìn chung, các tác giả đều đồng quan điểm khi cho rằng đây là hoạt động giáo dục theo lý thuyết hoạt động. Theo lí thuyết này, người học hình thành những năng lực, phẩm chất nhất định thông qua hoạt động.

Trong lí luận dạy học, khi trình bày quan niệm về phương pháp dạy học, nhiều học giả cho rằng, mục tiêu đầu tiên và cuối cùng của lý luận dạy học là phải tìm ra và nhận biết phương pháp dạy học mà ở đó giáo viên ít phải dạy hơn, học sinh học nhiều hơn... học sinh có nhiều tự do, niềm vui và tiến bộ thật sự hơn [1, tr.109]. Hoạt động trải nghiệm trong dạy học được coi là một trong những phương pháp dạy học đáp ứng yêu cầu đó.

Hoạt động trải nghiệm trong dạy học được xây dựng dựa trên các cơ sở về lý thuyết hành động, cơ sở về lý thuyết văn hóa - lịch sử và cơ sở về tâm lý học, giáo dục học. Được manh nha từ rất sớm nhưng đến giữa thế kỉ XIX, các lý thuyết và nguyên tắc giáo dục theo quan điểm đề cao vai trò của trải nghiệm trong giáo dục mới được chính thức công bố bởi công trình "Experience and Education" của tác giả John Deway. Tác phẩm đã chỉ ra rằng, với giáo dục truyền thống, người học trở nên bị động, thiếu sáng tạo, và xác định "giáo dục tốt nhất phải là sụ học tập trong cuộc sống”[4, tr.52]. 
Đặc biệt, tác giả David Kolb đã xây dựng thành công lý thuyết học từ trải nghiệm (Experiential learing) và nhấn mạnh "học tù trải nghiệm là quá trình học theo đó, kiến thức, năng lực được tạo ra thông qua việc chuyển hóa kinh nghiệm. Học tù trải nghiệm gần giống với học thông qua làm nhung khác ở chỗ nó gắn với kinh nghiệm và cảm xúc cá nhân"'[2]. Từ đó, Kolb xây dựng mô hình cho hoạt động trải nghiệm trong dạy học như sau:

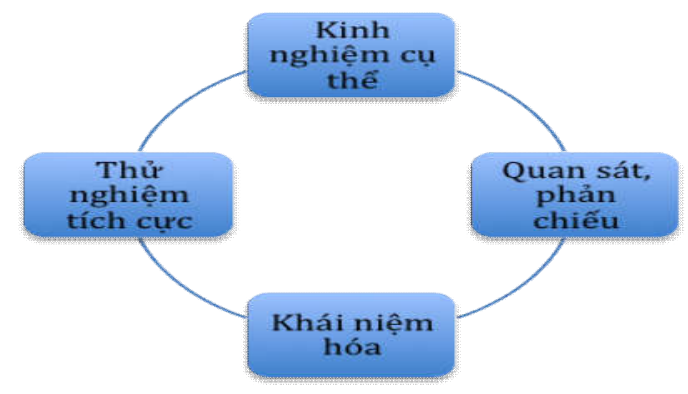

Mô hình 01: Mô hình học qua trải nghiệm

trong day học của David Kolb (nguồn [2])

Qua mô hình hoạt động học tập trải nghiệm của Kolb cho thấy, hoạt động gồm 4 nội dung (theo chiều kim đồng hồ), bắt đầu từ kinh nghiệm cu thể, quan sát phản chiếu, khái quát hóa kết thúc là thư nghiệm tích cưc. Các nội dung này tạo thành một chu trình khép kín. Khi thực hiện theo chu trình, người học có thể không cần xác định điểm nào là bắt đầu và bước tiếp theo là gì, nhưng phù hợp với đối tượng người học về nội dung học tập và điều kiện môi trường học tập. Với chu trình học từ trải nghiệm, chuyên gia, giáo viên các môn học có thể xây dựng quy trình tổ chức hoạt động học cho học sinh thông qua trải nghiệm.

Ở Việt Nam, hoạt động trải nghiệm trong dạy học được thể hiện trong những văn bản như Luật giáo dục Việt Nam, điều 3, 2010, Nghị quyết Hội nghị TW 8 khóa XI về đổi mới căn bản toàn diện giáo dục đào tạo... đề cập vấn đề thực hiện hoạt động trải nghiệm cho học sinh như là một phương pháp dạy học tích cực trong quá trình dạy học. Trong những năm gần đây, Bộ Giáo dục tổ chức nhiều hội thảo về Hoạt động trải nghiệm cho học sinh ("Tổ chức hoạt động giáo dục trải nghiệm sáng tạo của học sinh phổ thông”, năm 2014; "Tổ chức hoạt động giáo dục trải nghiệm sáng tạo khoa học kĩ thuật trong trường trung học, năm 2014), "Kĩ năng xây dựng và tổ chức các hoạt động trải nghiệm sáng tạo trong truờng trung học", năm 2015).... Nghiên cứu của các tác giả Phạm Minh Hạc, Nguyễn Thị Liên... cho thấy vai trò, vị trí quan trọng của việc tổ chức hoạt động trải nghiệm sáng tạo trong dạy học để phát triển năng lực, phẩm chất cho học sinh. Các nghiên cứu trên được triển khai theo hướng làm rõ cơ sở khái niệm, nội dung, hình thức tổ chức các hoạt động trải nghiệm trong giáo dục, nhưng chưa có công trình nào chuyên sâu nghiên cứu về tổ chức dạy học tiếng Việt cho lưu học sinh Lào học tại trường Đại học Tân Trào theo hoạt động này.

\subsection{Xây dụng hoạt động học tập trải nghiệm} theo chủ đề trong học phần 'Hội thoại' cho lưu học sinh Lào

Trên cơ sở nền tảng mối quan hệ hữu nghị Việt Lào, tỉnh Tuyên Quang và tỉnh Xiêng Khoảng đã thực hiện các nội dung Biên bản ghi nhớ hợp tác đã ký kết, thời gian qua, Trường Đại học Tân Trào đã tiếp nhận và đào tạo 5 khóa sinh viên Lào. Trường Đại học Tân Trào đã tổ chức đào tạo tiếng Việt cho sinh viên tỉnh Xiêng Khoảng trong năm đầu tiên, sau đó, các em sẽ lựa chọn chuyên ngành phù hợp để theo học.

Chương trình dạy Tiếng Việt co sở cho lưu học sinh Lào gồm 5 học phần: Ngũ âm tiếng Việt ; Hội thoại; Ngũ pháp; Huớng dẫn một số thể loại văn bản và rèn kĩ năng nghe, nói, đọc, viết; Thuật ngũ chuyên ngành. Trong phạm vi bài viết này, chúng tôi xây dựng quy trình tổ chức hoạt động trải nghiệm dạy một chủ đề của học phần 2: Hội thoại dạy Tiếng Việt cơ sở cho lưu học sinh Lào tại trường Đại học Tân Trào.

Trong hoạt động giao tiếp bằng ngôn ngữ, hội thoại là hoạt động giao tiếp phổ biến nhất, căn bản và thuoòng xuyên nhất của con người. Các nhà ngôn ngữ học ở nước ngoài như: N. Chomsky, J. Austin, J.Fillmore, H.P. Grice đã có những đóng góp cho nghiên cứu về lý thuyết hội thoại và tạo cơ sở cho nghiên cứu về hội thoại ở Việt Nam. Các nhà Việt ngữ học như Đỗ Hữu Châu, Cao Xuân Hạo, Nguyễn Thiện Giáp, Nguyễn Văn Hiệp... đã có những công trình nghiên cứu cơ bản về lí thuyết hội thoại. Các tác giả đưa ra nhiều cách hiểu khác nhau về hội thoại, nhưng tựu chung lại về nội hàm khái niệm cá tác giả đưa ra đều giống nhau ở chỗ cho rằng, hội thoại (conversation) là hoạt động giao tiếp bằng lời, giữa những người tham gia giao tiếp, trong một ngữ cảnh nhất định, nhằm một mục đích nào đó.

Học phần Hội thoại dạy lưu học sinh Lào biết vận dụng một cách linh hoạt nguyên tắc sử dụng TV lời nói vào những chủ đề hội thoại, giúp các em có kĩ năng sử dụng chuẩn tiếng Việt thành thạo. Đối với lưu học sinh Lào đến học tập tại trường Tân Trào, tiếng Việt là một ngoại ngữ. Học phần Hội thoại có 19 chủ đề, mục tiêu 
của học phần này là giúp các lưu học sinh Lào mở rộng vốn từ và rèn luyện các kĩ năng sử dụng tiếng Việt vào hội thoại trong những môi trường giao tiếp khác nhau. Đồng thời, cùng với các học phần khác, các em có kĩ năng sử dụng tiếng Việt để học các chuyên ngành và nghiên cứu khoa học ở trường đại học Tân Trào. Mỗi khóa học, trường Đại học Tân Trào chỉ tiếp nhận 5 lưu học sinh, vì vậy, trong việc dạy tiếng Việt cho các em, yếu tố chất lượng được đặt lên hàng đầu. Đây cũng là một điều kiện thuận lợi để có thể tổ chức hoạt động trải nghiệm cho các em và giáo viên có điều kiện kèm cặp, giúp đỡ từng em. Trong khuôn khổ bài viết, chúng tôi ứng dụng xây dựng hoạt động trải nghiệm nội dung bài 11: Hội thoại về tham quan du lịch. Nội dung bài hội thoại 11 được bố trí 14 tiết với 3 phần, phần 1: các tình huống hội thoại đi tham quan, phần 2: từ vựng, phần 3 : ghi chú ngữ pháp. Với bài này, giáo viên cung cấp cho các em các tình huống hội thoại giả định mà giáo viên là người xây dựng kịch bản và các em sắm vai giao tiếp khi đi tham quan một số di tích lịch sử, danh lam thắng cảnh. Đồng thời, vốn từ vựng về tham quan du lịch của các em được sử dụng hợp lý, đúng ngữ pháp.

Úng dụng hoạt động trải nghiệm trong dạy học nội dung hội thoại bài 11, chúng tôi tổ chức hoạt động dạy học theo cách có chủ định của giáo viên, giúp các em lưu học sinh Lào mở rộng vốn từ, phát triển năng lực sử dụng tiếng Việt trong hoạt động giao tiếp. Trên cơ sở mô hình học qua trải nghiệm trong dạy học của David Kolb, chúng tôi xây dựng cho lưu học sinh Lào trực tiếp tham quan du lịch một số di tích lịch sử, danh lam thắng cảnh tại thành phố Tuyên Quang. Để thực hiện được hoạt động này, giáo viên chuẩn bị theo kế hoạch học tập với mục tiêu tạo điều kiện tất cả lưu học sinh phải tìm tòi, trình bày, chia sẻ và phỏng vấn bạn để thực hiện nhiệm vụ học tập. Nội dung bài hội thoại 11 có thể đặt thành nhiều câu hỏi nghi vấn cần được giải đáp, nhiều tình huống hội thoại về tham quan du lịch. Các luu học sinh Lào cần chuẩn bị chuẩn bị tài liệu học tập, giấy Ao, phương tiện hỗ trợ máy projector.

\section{- Các buoóc coo bản tiến hành bài học}

+ Bước 1: Giáo viên yêu cầu học sinh tìm hiểu trước về Bảo tàng tỉnh Tuyên Quang, Đền thờ chủ tịch Hồ Chí Minh qua các lưu học sinh Lào khóa trước và các sinh viên Việt Nam. Để chuẩn bị cho hoạt động trải nghiệm, các em được mở rộng một số từ vựng về tham quan, du lịch từ việc tự tìm hiểu này. Nhiệm vụ mỗi bạn là trao đổi, thảo luận, dự thảo ra một bộ câu hỏi xoay xung quanh nội dung bài học. Mục đích là mở rộng vốn từ về tham quan dụ lịch và thực hiện hội thoại.
Giáo viên tạo môi trường học tập cho học sinh hoạt động cùng nhau, hoạt động hợp tác giữa thầy và trò, hoạt động hợp tác giữa trò và trò. Để thực hiện điều đó, giáo viên tổ chức cho học sinh tham quan Bảo tàng tỉnh Tuyên Quang, Đền thờ chủ tịch Hồ Chí Minh. Nhờ đó, các em được nghe giới thiệu khái quát về lịch sử hình thành của bảo tàng, về các hiện vật hiện đang được trưng bày, về các di tích lịch sử ở Bảo tàng. Đây chính là hoạt động trải nghiệm cụ thể. Trong hoạt động này, các lưu học sinh Lào được mở rộng vốn từ và môi trường giao tiếp thông qua các trải nghiệm mới về các khu bảo tàng, di tích. Đồng thời, các em ghi chép những từ mới, những cách nói của hướng dẫn viên. Từ đó, các em có được những kinh nghiệm về chủ đề hội thoại này. Những từ ngữ mà các em có được trong hoàn cảnh giao tiếp cụ thể giúp các em nhớ lâu, khắc sâu.

+ Bước 2: Sau khi tạo được những kinh nghiệm cho bản thân về hội thoại chủ đề tham quan, du lịch, các lưu học sinh Lào được giáo viên tổ chức thảo luận. Giáo viên ghép đôi các lưu học sinh Lào với nhau và các em tự tiến hành phỏng vấn với các câu hỏi do mình đặt ra (theo kĩ thuật phỏng vấn ba bước: three - step interview của Spencer Kagan - chuyên gia tâm lý học Spencer Kagan thiết kế vào cuối những năm 60 của thế kỷ XX). Theo kĩ thuật này, các thành viên trong một cặp đổi vai cho nhau, người phỏng vấn trở thành người trả lời và ngược lại. Nội dung trao đổi được các thành viên ghi chép lại. Nội dung trao đổi về các di tích các em được tham quan. Đây là bước mà các lưu học sinh Lào kiểm tra cho nhau một cách hệ thống những nội dung mà bản thân các em đã quan sát, đã trải qua. Các em được sử dụng các phương tiện như giấy Ao, phương tiện hỗ trợ máy projector trong khi chuẩn bị thảo luận. Giáo viên là người hướng dẫn, điều chỉnh các em khi các em phỏng vấn nhau. Ở bước này, sự hợp tác giữa trò với trò là chủ yếu. Các em tương tác, trao đổi để tìm ra và miêu tả những đặc điểm của các di tích các em đã tham quan một cách hệ thống.

+ Bước 3: Sau bước 2, các lưu học sinh chia sẻ câu trả lời của mình với cả nhóm dưới sự tổ chức của giáo viên. Mỗi người tự trình bày các nội dung thu được từ bước 2 thành một bài giới thiệu về một trong những di tích mà các bạn được tham quan. Các thành viên khác trong lớp hỗ trợ, giúp đỡ, cộng tác với nhau hoàn thành nội dung, đồng thời bổ sung những ý tưởng mới thông qua trao đổi được của bạn. Lúc này, các em đã được trải nghiệm, được giao tiếp và thực hiện bài nói một cách tương đối độc lập.

\footnotetext{
+ Bước 4: Thử nghiệm tích cực
} 
Giáo viên tổ chức cho lưu học sinh viên đóng vai: một bạn đóng vai hướng dẫn viên du lịch, các bạn khác đóng vai khách du lịch. Các bạn chuẩn bị và thực hiện các hoạt động giao tiếp về chủ đề mà các bạn đã trải nghiệm, tìm hiểu. Các lưu học sinh Lào tự tổng hợp những từ mới mà các em học tập được trong buổi học và những ghi chú về ngữ pháp. Giáo viên là người tổ chức, điều khiển hoạt động hội thoại của các em, nhận xét, đánh giá, chính xác hoá kiến thức. Đồng thời, nhận xét hiệu quả làm việc từng lưu học sinh khi các em thực hiện giao tiếp về chủ đề tham quan du lịch bằng tiếng Việt. Kết thúc bước 4, các lưu học sinh Lào đã hoàn thành quá trình học tập nội dung hội thoại bài 11 . Có thể khẳng định, những từ vựng mới và hoạt động giao tiếp về chủ đề tham quan du lịch được các em tiếp thu một cách chủ động bởi "nhũng tri thức đạt được thông qua quá trình làm việc mói chính là tri thức thật" [1].

\section{Kết luận}

Trước hết, cần khẳng định hoạt động trải nghiệm trong giáo dục có cơ sở từ lí luận dạy học, lý thuyết giáo dục và phù hợp với xu hướng quốc tế trong việc cải cách giáo dục bởi khả năng phát triển năng lực cho người học mà hoạt động này mang lại. Việc xây dựng hoạt động trải nghiệm trong dạy hội thoại cho lưu học sinh Lào qua nội dung bài 11 , học phần 2 môn Tiếng Việt co sở có ưu điểm nổi bật là lưu học sinh Lào tự tích lũy được kinh nghiệm sử dụng tiếng Việt thông qua trải nghiệm thực tế; đồng thời, lưu học sinh Lào chủ động chiếm lĩnh từ mới và phát triển hội thoại. Năng lực giao tiếp bằng tiếng Việt của lưu học sinh Lào được phát triển và nâng cao. Đây là hoạt động bổ ích, lý thú sau những giờ học căng thẳng, tạo điều kiện để sinh viên nước Lào hiểu thêm về lịch sử, văn hóa, con người Tuyên Quang nói riêng và đất nước Việt Nam nói chung.

\section{TÀI LIỆU THAM KHẢO}

1. Bernd Meier, Nguyễn Văn Cường (2011), Lí luận dạy học kĩ thuật, C Eigenverlag, Berlin. Printed in Germany.

2. D.A. Kolb (1984), Experiential learing, San Francisco Jossay-Bas.

3. Phạm Minh Hạc (1997), Tâm lý học Vurgotxki, NXB Giáo dục, Hà Nội.

4. John Dewey (2012), Kinh nghiệm và giáo duc, dịch giả Phạm Tuấn Anh, NXB DTBooks và Trẻ.

6. Trường Đại học Tân Trào (2014), Giáo trình tiếng Việt co sở dành cho luu học sinh Lào, giáo trình lưu hành nội bộ.

\section{Application of experimental activities in teaching Vietnamese for Laos students at Tan Trao university}

Nguyen My Viet

\section{Article info}

Recieved:

25/5/2019

Accepted:

10/6/2019

Keywords:

creative experience;

competency;

conversation;

teaching Vietnamese;

Laos students.

\begin{abstract}
Creative experience is an activity in theory. The learners, form certain capabilities and qualities, through learning activities According to the theoretical basis of modern education on creative experience activities, the article builds the process of organizing creative experience activities in teaching conversation in Vietnamese program for Laos students.So it can help them develop their ability in using Vietnamese in conversation and during studying and researching at Tan Trao University, Tuyen Quang province.
\end{abstract}

